\section{A Minimalistic Hydrolase based on Co-Assembled Cyclic Dipeptides}

\author{
Alexander J. Kleinsmann ${ }^{[b]}$ and Boris J. \\ Nachtsheim ${ }^{\star[a]}$
}

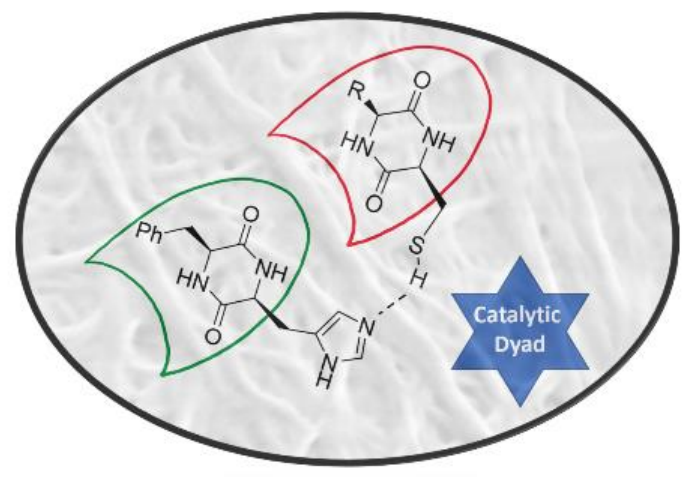

Abstract: The self-assembly of small peptides into larger aggregates is an important process for the fundamental understanding of abiogenesis. In this article we demonstrate that blends of cyclic dipeptides (2,5-diketopiperazines - DKPs) bearing either histidine or cysteine in combination with a lipophilic amino acid form highly stable aggregates in aqueous solution with esterase-like activity. We demonstrate that the catalytic activity is based on an intermolecular cooperative behavior between histidine and cysteine. A high control of the molecular arrangement of the peptide assemblies was gained by $\mathrm{C}-\mathrm{H}-\pi$ interactions between Phe and Leu or Val sidechains, resulting in a significant increase in catalytic activity. These interactions were strongly supported by Hartree-Fock calculations and finally confirmed via ${ }^{1} \mathrm{H}$-NMR HRMAS NOE spectroscopy.

The transition of simple small molecular building blocks, in particular fatty-, amino- and nucleic acids, into self-replicating systems with an autonomous metabolism is the critical step for the emergence of the first living cells with a minimalistic genotype and phenotype. ${ }^{[1]}$ The initial manifestation of small peptides as enzyme precursors that could have provided important catalytic properties for autonomous self-replicating systems is still underexplored. ${ }^{[2],[3]}$ Here, self-assembly processes that form higher ordered aggregates from spontaneously formed small oligopeptides through intermolecular $\mathrm{H}$-bonding interactions is believed to be an important initial step. ${ }^{[4 a-c, 2,4 d]}$ In this regard, cyclic dipeptides (2,5-diketopiperazines - DKPs) are observed

[a] Prof. Dr. Boris J. Nachtsheim

Institut für Organische und Analytische Chemie Universität Bremen

Leobener Straße 7, 28359 Bremen, Germany nachtsheim@uni-bremen.de

[b] Dr. Alexander J. Kleinsmann Institut für Organische Chemie Universität Tübingen

Auf der Morgenstelle 18, 72076 Tübingen, Germany frequently as undesired side-products during peptide formation and under prebiotic conditions, ${ }^{[5]}$ in particular as degradation products of small oligopeptides. ${ }^{[6]}$ In addition, they have been found on the Yamato-791198 and Murchison carbonaceous chondrites. ${ }^{[7]}$ We recently demonstrated that a variety of Phecontaining DKPs form highly stable aggregates in aqueous solutions. ${ }^{[8]}$ Their self-aggregation is the result of strong $\mathrm{H}$ bonding interactions between the cyclic amides and additional $\pi-$ $\pi-$ or $\mathrm{C}-\mathrm{H}-\mathrm{\pi}$-interactions between the Phe sidechains. For proving the relevance of DKPs in the context of abiogenesis, their catalytic properties must be elucidated. So far their catalytic activity has only been demonstrated by Lipton and co-workers in solution for the asymmetric Strecker reaction. ${ }^{[9]}$ Presuming their high tendency to aggregate in water into a defined molecular arrangement, we proposed that simple blends of two DKPs composed of proteinogenic a-amino acids with lipophilic side chains and differing "functional" side chains should render enzyme-like catalytic activity in the co-assembled state through intermolecular cooperative effects.

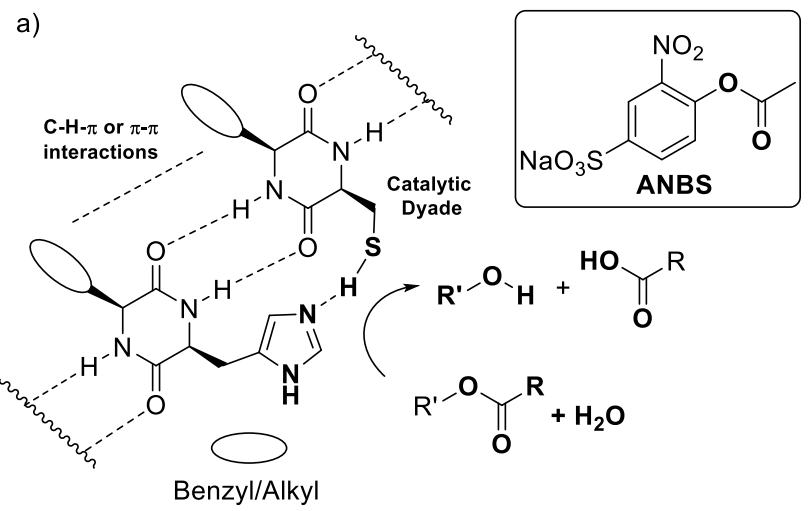

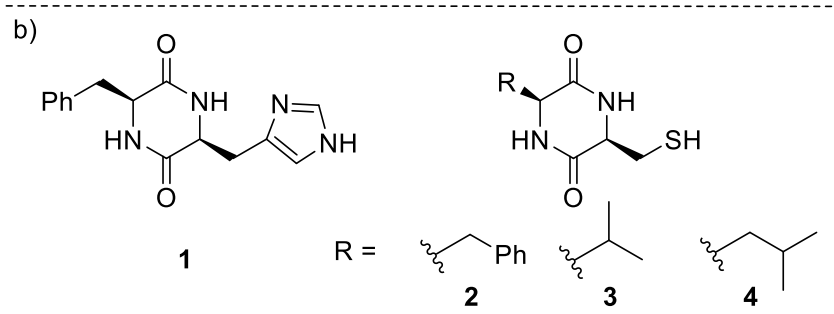

Figure 1. (a) A DKP-based mimic of a catalytic dyade (b) Investigated DKP structures

To verify this working hypothesis, we generated a minimalistic hydrolase mimic (Figure 1a). In the catalytically active side of hydrolases, imidazoles of His-residues are in close proximity to Ser, Cys or Asp side-chains as the structural basis for catalytic dyads or triades. Artificial enzymes, in particular esterases based on the self-assembly of short oligopeptides have been described frequently. ${ }^{[10]}$ Commonly, lipophilic tripeptides, amphiphilic oligopeptides or amyloid-forming peptides are necessary to generate self-assembled nanostructures with esterase-like activity. ${ }^{[11]}$ Catalytically active aggregates can also be formed based on artificial dendrimers, by fixation of a peptide onto nanoparticles ${ }^{[12]}$ or the generation of other amino acid-derived hybrids. ${ }^{[13],[14]}$ The relevance of these approaches in abiogenesis is questionable due to the artificial nature of the underlying 
molecular building blocks. To the best of our knowledge simple dipeptides without non-natural synthetic modifications are not known as minimalistic esterase mimics. Based on our recent findings towards the outstanding self-aggregation properties of DKPs, we combined His-DKP 1 and Cys-DKPs (2, 3 and 4) as shown in Figure 1b. These three different blends [1+2], [1+3] and $[1+4]$ should give co-assembled nanostructures with a putative esterase activity. ${ }^{[15]}$ We first investigated the principle coaggregation properties of all three blends. Co-assembly was verified through hydrogel formation and subsequent investigation of the freeze-dried hydrogels via SEM (Figure 2). All three blends formed stable hydrogels through a simple heating/cooling cycle in pure water at concentrations between 80 and $106 \mathrm{mM}$. SEM and TEM images showed the appearance of nanofibers with varying average diameters ([1+2]: $12.3 \mathrm{~nm},[\mathbf{1 + 3}]: 32.6 \mathrm{~nm}$ and [1+4]: $21.4 \mathrm{~nm}$ ) (for detailed analysis of representative SEM-images see ESI).
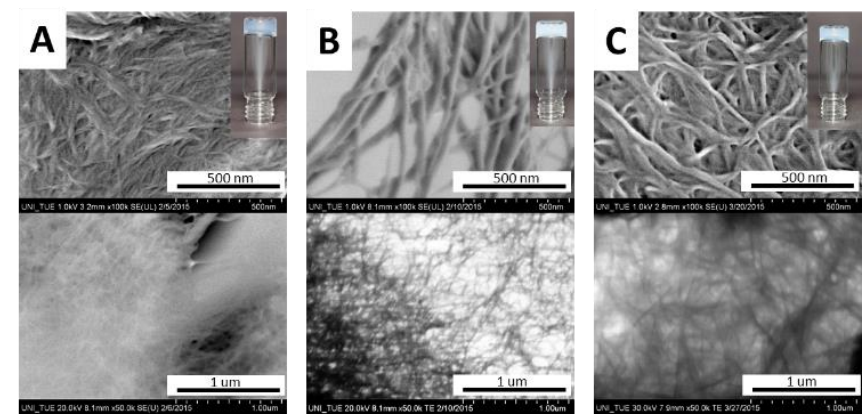

Figure 2. SEM- and TEM-images of co-assembled DKP-blends A: [1+2]; $B$ : $[1+3]$; C: $[1+4]$

To investigate esterase-like activity of the co-aggregates, the hydrolysis of sodium 4-acetoxy-3-nitrobenzenesulfonate (ANBS, Figure 1a), a water- soluble derivative of the common model compound 2,4-dinitrophenyl acetate (DNPA), was chosen as the model reaction. A solution of ANBS was added on top of the preformed hydrogel and reaction kinetics were monitored by UV/Vis. Initial Job's plot analysis revealed a maximum initial rate constant $\mathrm{v}_{0}$ at $\mathrm{X}=0.4$ for blend [1+2] and $\mathrm{X}=0.5$ for blends [1+3] and $[1+4]$ (Figure $3-\mathrm{A}$ ). We then investigated the $\mathrm{pH}$ dependency of the ester hydrolysis (Figure $3-B$ ). While with [1+2] $\mathrm{v}_{0}$ reaches a maximum at $\mathrm{pH}=7.50$, co-assemblies of [1+3] and $[1+4]$ reached explicit maxima at slightly lower $\mathrm{pH}$-values $(7.25$ and 7.38).
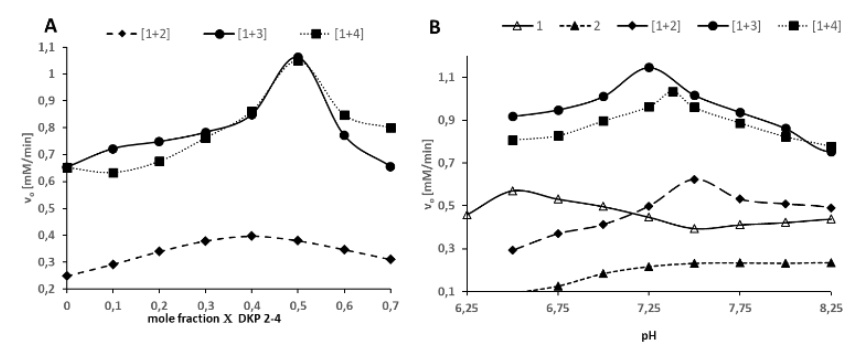

Figure 3. A: Job's plot analysis of DKP-blends [1+2], [1+3] and [1+4]. B: $\mathrm{pH}-$ dependency of the initial rate constants.
In sharp contrast, $v_{0}$ of pure self-assembled $\mathbf{1}$ has a maximum at 6.50 which corresponds well to the $\mathrm{pK}_{\mathrm{a}}$-value of His. For selfassembled DKP $2 \mathrm{v}_{0}$ increases until $\mathrm{pH} 7.5$ and reaches a plateau. The broad maximum of Job's plot analysis for blend [1+2] together with the slight shift from the theoretical optimal ratio of both DKPs from 1:1 as observed for $[1+3]$ and $[1+4]$ is indicative for a random distribution of 1 and 2 within the fibrous network (Figure $4-A$ ). The sharp maxima at $X=0.5$ for $[1+3]$ and $[1+4]$ on the other hand indicate a highly defined co-assembly of both DKPs (Figure 4 - B).
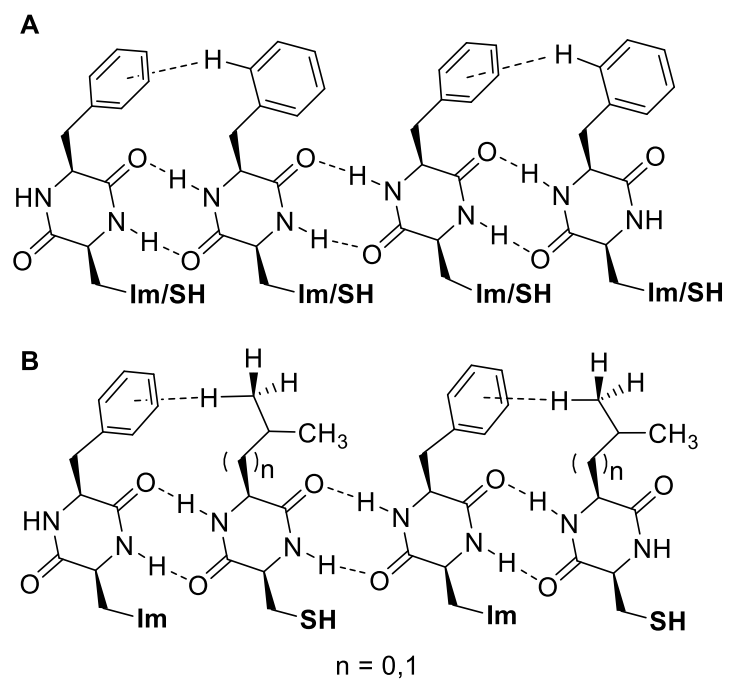

Figure 4. A: Random distribution of DKPs 1 and 2 within the co-assembly. B: Alternating distribution of DKPs $\mathbf{1}$ and $\mathbf{3}$ or $\mathbf{4}$ within the co-assembly.

This defined alternating co-assembly should also result in higher catalytic performance of blends $[1+3]$ and $[1+4]$, as already indicated by the significantly higher $\mathrm{v}_{0}$-values. Next, we wanted to compare $v_{0}$ of the DKPs between the co-assembled hydrogel state and a solution by disturbing the co-assembly process through DMF addition. In general, $v_{0}$ should be reduced for the hydrogels since substrate availability is initially strongly limited by diffusion processes. In addition, the accessibility of the catalytically active His and Cys residues should be strongly limited in the self-assembled hydrogel state through intermolecular interactions of individual strands to form the three-dimensional network. As an initial control experiment, we tested the catalytic activity of pure His-DKP 1 in solution (Figure $5-\mathrm{A}$, dotted lines). Even though 1 accelerated ANBS hydrolysis, it cannot be defined as catalyst. The solution exhibits a fast initial reaction turnover in the first 10 minutes and finally approaches asymptotically a substrate conversion that matches the total DKP concentration. Hence, only one turnover is observed. With the same absolute molarity, the corresponding hydrogel of $\mathbf{1}$ shows an inferior substrate conversion, also with a strongly decelerating slope finally converging to an overall conversion close to the DKP concentration. This diminished reactivity strongly indicates the lower accessibility of the His-residues in the aggregated state. The observed saturation in both the solution and the gel state of 1 indicates a quick $\mathrm{N}$-acetylation of the His-residue followed by a very slow deacetylation, excluding a truly catalytic behaviour. 
Next we investigated the corresponding blends (Figure 5, A-C). In all cases the self-assembled blended DKPs were compared with the corresponding DKPs kept in solution as a control. As already observed for pure 1, all blended solutions, even though accelerating ester hydrolysis, provided only one turnover. Real catalytic behaviour is only observed for blended hydrogels. For [1+2] total conversion of the solution again converges to the initial DKP-concentration while in the co-assembled state product concentration exceeds DKP-concentration after 35 min (Figure 5 - B). A similar catalytic behaviour was observed for [1+3] and $[1+4]$, although, as already indicated in Figure 3 - A, ANBS hydrolysis was throughout faster, exceeding the initial DKP concentration after 20-25 min. In sharp contrast to pure 1 and [1+2], initial hydrolysis rates using the co-assembled blends [1+3] and $[1+4]$ were comparable to the solution phase experiments (Figure $5-\mathrm{C}$ and D). Overall, the co-assembled blend [1+4] shows the best results in direct comparison with the corresponding solution phase and in direct comparison to the other blends.
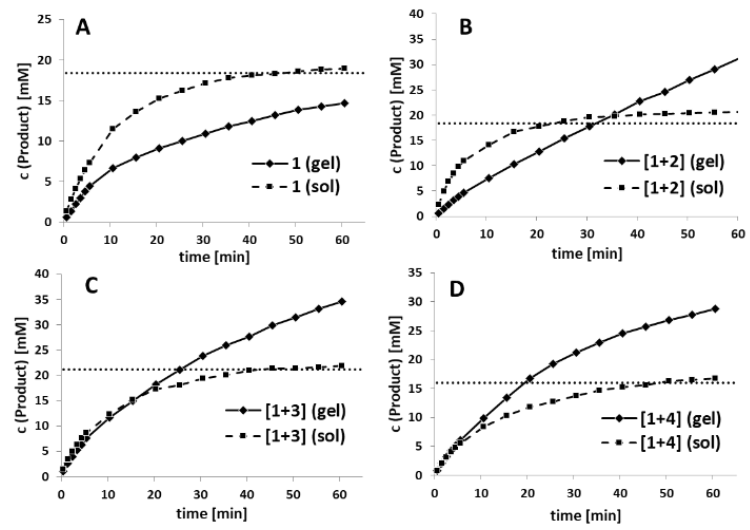

Figure 5. Product formation in ANBS hydrolysis, c (ANBS) $=60 \mathrm{mM}$; solid lines: reaction was performed in the self-assembled hydrogel (gel); dashed lines: reaction was performed in solution (sol) (HEPES:DMF $=1: 1, \mathrm{~V}=1.25 \mathrm{ml}$ ); dotted lines: total DKP concentration referenced to the total volume; $\mathbf{A}: \mathbf{1}, \mathrm{pH}=$ 6.50, c (1-hydrogel) = $92 \mathrm{mM}$; B: [1+2] (1.5:1), $\mathrm{pH}=7.50, \mathrm{c}=92 \mathrm{mM}$; $\mathbf{C}:$ [1+3] (1:1), $\mathrm{pH}=7.25, \mathrm{c}=106 \mathrm{mM}$; $\mathbf{D}:[1+4](1: 1), \mathrm{pH}=7.38, \mathrm{c}=80 \mathrm{mM}$. Product conversion was detected via UV/Vis at $\lambda=406 \mathrm{~nm}$. In all experiments background hydrolysis of ANBS was measured in the corresponding buffers at the same $\mathrm{pH}$ with identical substrate concentration and subtracted from the measured values.

For a more precise comparison of their catalytic efficiency, $v_{0}$ was investigated in dependence of the substrate concentration at the optimal $\mathrm{pH}$ and ratio for each blend. The Michaelis-Menten enzyme kinetics model was used to calculate the rate constants for all co-assembled hydrogels. In all blends, catalyst turnover became the rate-limiting step at very high substrate concentrations, a typical behaviour for enzyme-catalysed reactions (see ESI - Table S2). Michaelis Menten constants $\left(K_{M}\right)$, rate constants $\left(\mathrm{K}_{\text {cat }}\right)$ as well as the catalytic efficiencies $\left(\mathrm{K}_{\mathrm{cat}} / \mathrm{K}_{\mathrm{M}}\right)$ are given in Table 1. The highest substrate-affinity and the highest catalytic efficiency was once again observed for blend [1+4] $\left(K_{M}\right.$ $=6.81)$. $\mathrm{K}_{\text {cat }}$ values between $[1+3]$ and $[1+4]$ differ only insignificantly but $K_{M}$ is twofold higher for [1+3]. This is indicative for a significantly weaker substrate affinity and might be the result of sterically more favourable or multiple $\mathrm{C}-\mathrm{H}-\mathrm{m}$-interactions between 1 and $\mathbf{4}$ which subsequently leads to a closer proximity of the imidazole and thiol functionalities at the opposite site of the DKP.

Table 1: Summary of Michaelis-Menten kinetics.

\begin{tabular}{llll}
\hline Hydrogel & $\begin{array}{l}\mathrm{K}_{\mathrm{M}} \\
\left(10^{-3} \mathrm{M}\right)\end{array}$ & $\begin{array}{l}\mathrm{K}_{\text {cat }} \\
\left(10^{-3} \mathrm{~s}^{-1}\right)\end{array}$ & $\begin{array}{l}\mathrm{K}_{\text {cat }} / \mathrm{K}_{\mathrm{M}} \\
\left(10^{-1} \mathrm{M}^{-1} \mathrm{~s}^{-1}\right)\end{array}$ \\
\hline$[\mathbf{1 + 2}]^{\mathrm{a}}$ & 8.51 & 0.73 & 0.86 \\
{$[\mathbf{1 + 3}]^{\mathrm{b}}$} & 12.18 & 1.60 & 1.31 \\
{$[\mathbf{1 + 4}]^{\mathrm{c}}$} & 6.81 & 1.46 & 2.14 \\
\hline
\end{tabular}

a $1.5: 1$ ratio of 1 and $2, \mathrm{pH}=7.50 ; \mathrm{b}: 1: 1$ ratio of $\mathbf{1}$ and $3, \mathrm{pH}=7.25 ; \mathrm{c}: 1: 1$ ratio of 1 and $\mathbf{4}, \mathrm{pH}=7.38$.

A
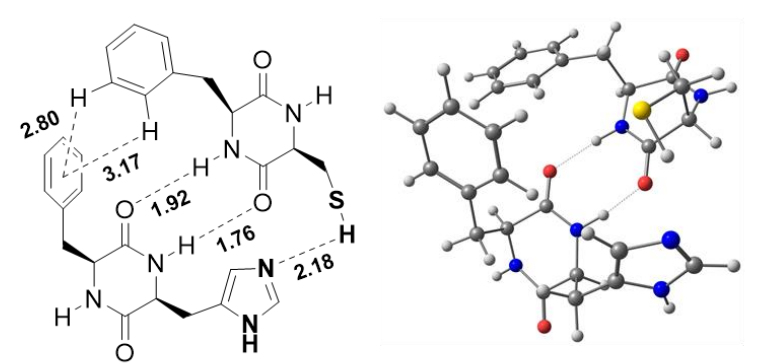

B
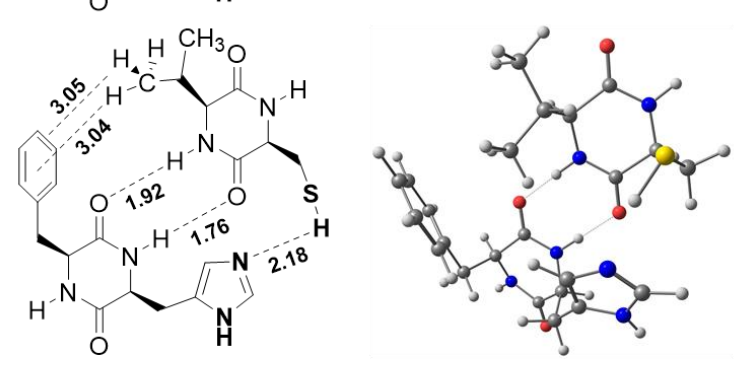

C
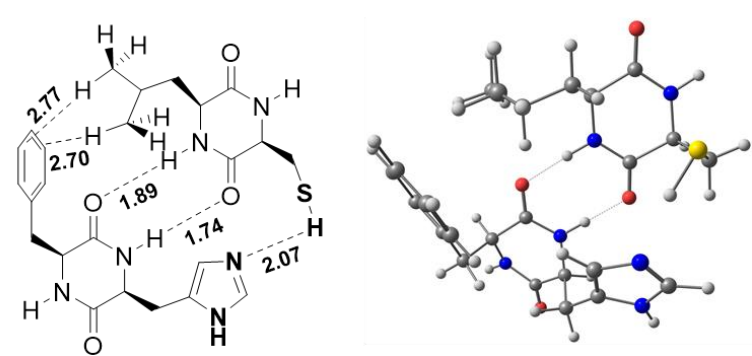

Figure 6. Calculated structures of DKP-dimers. A: [1+2]; B: [1+3]; C: [1+4]. Structures were calculated using the semi-empirical HF-3c functional in the gas phase.

To verify this hypothesis, gas phase calculations based on the low cost Hartree-Fock/minimal basis set composite method HF-3C which shows excellent performance for noncovalent interactions ${ }^{[16]}$ have been accomplished for dimers of [1+2], [1+3] and [1+4] (Figure 6). Each energy minimized structure confirms two central intermolecular $\mathrm{H}$-bonds between the two cyclic amides with typical O-H-distances ranging from 1.74 to $1.92 \AA$. $\mathrm{H}$ Bonds between the lipophilic amino acids are significantly longer (1.89-1.92 $\AA$ ) than the $\mathrm{H}$-bonds between the His and Cys amino 
acids $(1.74-1.76 \AA$ ). As predicted, all lipophilic side chains show significant $\mathrm{C}-\mathrm{H}-\mathrm{m}$-interactions. For $[1+2]$ two $\mathrm{C}-\mathrm{H}-\mathrm{m}$-interactions of the ortho- and meta protons of the Phe side chain in $\mathbf{2}$ and the $\pi$-system of the Phe side chain in $\mathbf{1}$ give a disordered T-shape geometry between the two benzene rings with $\mathrm{C}-\mathrm{H}$ - $\mathrm{m}$-distances of 2.80 and $3.17 \AA$. In the calculated structure of [1+3] two significant $\mathrm{C}-\mathrm{H}-\mathrm{m}$-interaction between two $\mathrm{C}^{-} \mathrm{H}_{\gamma}$ protons of the terminal $\mathrm{CH}_{3}$-group of the $\mathrm{Val}$ side chain in $\mathbf{3}$ and the benzene ring in 1 exist. The calculated $\mathrm{C}-\mathrm{H}$ - $\mathrm{m}$-distances to the centroid of the benzene ring is $3.04 \AA$ and $3.05 \AA$ to the centroid of the C3C4-m-bond. For [1+4], two C-H-m-interaction are calculated with $\mathrm{C}-\mathrm{H}$ - $\mathrm{T}$-distance of 2.70 and $2.77 \AA$ between $\mathrm{C}-\mathrm{H}_{\delta}$ protons of both terminal $\mathrm{CH}_{3}$ groups and two distinct $\mathrm{C}-\mathrm{C}$ - $\mathrm{m}$-bonds of Phe. All distances are in good agreement with typical average distances of $\mathrm{C}-\mathrm{H}-\mathrm{T}$ interactions as observed in solid state protein structures. ${ }^{[17]}$ Obviously, the additional methylene group in the side chain of $\mathbf{4}$ allows a significantly stronger $\mathrm{C}-\mathrm{H}-\mathrm{m}$-interaction as implicated by shorter $\mathrm{C}-\mathrm{H}$-centroid distances. In all blends, combination of the two central amide hydrogen bonds and the additional $\mathrm{C}-\mathrm{H}-\mathrm{m}$-interaction arranges the functional imidazole and thiol functionalities into close proximity. Calculated $\mathrm{S}-\mathrm{H}-\mathrm{N}$ distances vary from $2.18 \AA$ in $[1+2]$ and [1+3], and $2.07 \AA$ for $[1+4]$. It has to be mentioned, that the horizontal dimension of these calculated single-strands (approx. $1 \mathrm{~nm}$ ) is one dimension below the observed fibre thickness as observed via SEM and TEM. Thus, further inter-strand interactions must be operational which strongly limits the true accessibility of the catalytically active sides in the self-assembled state. Under this premise it is even more surprising that blends $[1+3]$ and $[1+4]$ show similar initial hydrolysis rates in comparison to the corresponding DKPs kept in solution. To finally verify that the calculated alternating coassembly in [1+3] and [1+4] is based on $\mathrm{C}-\mathrm{H}$ - $\pi$-interactions, ${ }^{1} \mathrm{H}$ HRMAS NOESY experiments of the co-assembled hydrogels were performed in $\mathrm{D}_{2} \mathrm{O}$ (Figure 7). Clearly, the strongest NOE correlation was observed between $\mathrm{C}-\mathrm{H}_{\gamma}$ of $\mathbf{3}$ or $\mathrm{C}-\mathrm{H}_{\delta}$ of $\mathbf{4}$ and $\mathrm{C}$ $\mathrm{H}_{\text {aryl }}$ of 1 .
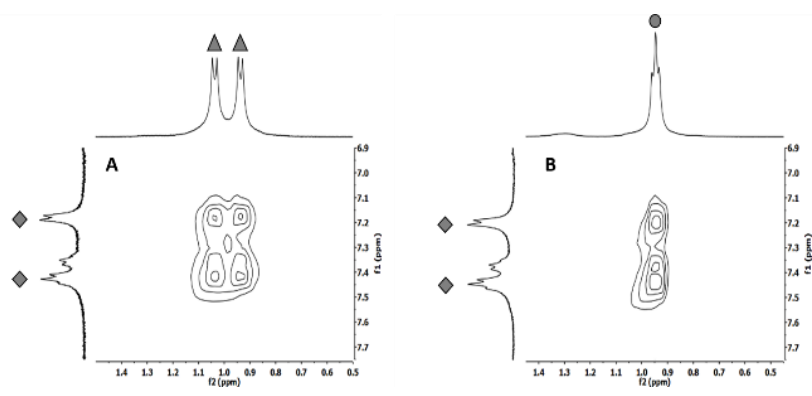

Figure $7 \mathbf{A}$ : Detail magnifications of ${ }^{1} \mathrm{H}$ HRMAS NOE spectra in $\mathrm{D}_{2} \mathrm{O}$ of $\mathbf{A}$ : Hydrogel [1+3] (1:1) and $\mathbf{B}$ : Hydrogel [1+4] (1:1); diamonds: aromatic protons of the Phe sidechain of 1, triangles: $\mathrm{C}^{-} \mathrm{H}_{\gamma}$ protons of the Val sidechain of $\mathbf{3}$, circles: $\mathrm{C}-\mathrm{H}_{\delta}$ protons of the Leu sidechain of 4 .

In summary we described the most minimalistic peptide selfassembly with an enzyme-like activity. It is based on abiogenesis relevant cyclic dipeptides solely build from the proteinogenic amino acids Phe, His, Val, Leu and Cys. A high catalytic turnover is exclusively observed in the self-aggregated state for heterologous mixtures (blends) of His- and a Cys-containing cyclic dipeptides. Hartree-Fock calculations as well as HRMAS
NOE experiments strongly indicate that $\mathrm{C}-\mathrm{H}$ - $\mathrm{m}$-interactions as well as intermolecular amide hydrogen bonds are responsible for the heterologous self-aggregation which finally leads to a close proximity of His and Cys side chain to give a catalytic dyade. These findings offer a new perceptive toward a potential role of the so far undervalued role of cyclic dipeptides in chemical evolution and further implies the importance of self-assembled peptide aggregates in the pre-Darwian evolution.

\section{Experimental Section}

Experimental Detail can be found in the Supporting Information.

Keywords: Self-assembly; Esterase; Molecular Evolution; Hydrogel; Abiogenesis

[1] T. A. E. Jakschitz, B. M. Rode, Chem. Soc. Rev. 2012, 41, 5484

[2] G. Danger, R. Plasson, R. Pascal, Chem. Soc. Rev. 2012, 41, 5416.

[3] a) A. Brack, Pure Appl. Chem. 1993, 65, 1143; b) A. Brack, Chem Biodiversity 2007, 4, 665.

[4] a) B. M. Rode, Peptides 1999, 20, 773; b) I. Ghosh, J. Chmielewski, Curr. Opin. Chem. Biol. 2004, 8, 640; c) O. Carny, E. Gazit, FASEB J. 2005 19, 1051; d) J. Greenwald, M. P. Friedmann, R. Riek, Angew. Chem. Int. Ed. 2016, 55, 11609.

[5] a) A. Brack, K. W. Ehler, L. E. Orgel, J. Mol. Evol. 1976, 8, 307; b) A. L. Weber, L. E. Orgel, J. Mol. Evol. 1978, 11, 189; c) A. L. Weber, L. E. Orgel, J. Mol. Evol. 1979, 13, 185; d) A. L. Weber, L. E. Orgel, J. Mol. Evol. 1979, 13, 193; e) S. Steinberg, J. L. Bada, Science 1981, 213, 544; f) M. Nagayama, O. Takaoka, K. Inomata, Y. Yamagata, Orig. Life Evol. Biosph. 1990, 20, 249; g) J. Ying, R. Lin, P. Xu, Y. Wu, Y. Liu, Y. Zhao, Sci. Rep. 2018, 8, 936; h) Y. Furukawa, T. Otake, T. Ishiguro, H. Nakazawa, T. Kakegawa, Orig. Life Evol. Biosph. 2012, 42, 519.

[6] a) K. Kawamura, T. Nishi, T. Sakiyama, J. Am. Chem. Soc. 2005, 127, 522; b) K. Kawamura, H. Takeya, T. Kushibe, Adv. Space Res. 2009, 44, 267.

[7] A. Shimoyama, R. Ogasawara, Orig. Life Evol. Biosph. 2002, 32, 165.

[8] A. J. Kleinsmann, B. J. Nachtsheim, Chem. Commun. 2013, 49, 7818.

[9] a) M. S. Iyer, K. M. Gigstad, N. D. Namdev, M. Lipton, J. Am. Chem. Soc. 1996, 118, 4910; b) M. S. Iyer, K. M. Gigstad, N. D. Namdev, M. Lipton, Amino Acids 1996, 11, 259.

[10] a) M. Raynal, P. Ballester, A. Vidal-Ferran, P. W. N. M. van Leeuwen, Chem. Soc. Rev. 2014, 43, 1734; b) E. Kuah, S. Toh, J. Yee, Q. Ma, Z. Gao, Chem. Eur. J. 2016, 22, 8404; c) N. Singh, M. Kumar, J. F. Miravet, R. V. Ulijn, B. Escuder, Chem. Eur. J. 2017, 23, 981; d) M. D. Nothling, Z. Xiao, A. Bhaskaran, M. T. Blyth, C. W. Bennett, M. L. Coote, L. A. Connal, ACS Catal. 2018, 9, 168; e) O. Zozulia, M. A. Dolan, I. V. Korendovych, Chem. Soc. Rev. 2018, 47, 3621.

[11] a) K. S. Broo, H. Nilsson, J. Nilsson, A. Flodberg, L. Baltzer, J. Am. Chem. Soc. 1998, 120, 4063; b) B. Baumeister, N. Sakai, S. Matile, Org. Lett. 2001, 3, 4229; c) A. J. Nicoll, R. K. Allemann, Org. Biomol. Chem. 2004, 2, 2175; d) M. O. Guler, S. I. Stupp, J. Am. Chem. Soc. 2007, 129, 12082; e) Z. Huang, S. Guan, Y. Wang, G. Shi, L. Cao, Y. Gao, Z. Dong, J. Xu, Q. Luo, J. Liu, J. Mater. Chem. B 2013, 1, 2297; f) C. Zhang, X. Xue, Q. Luo, Y. Li, K. Yang, X. Zhuang, Y. Jiang, J. Zhang, J. Liu, G. Zou et al., ACS nano 2014, 8, 11715; g) M. Matsumoto, S. J. Lee, M. L. Waters, M. R. Gagné, J. Am. Chem. Soc. 2014, 136, 15817; h) M. Bélières, N. Chouini-Lalanne, C. Déjugnat, RSC Adv. 2015, 5, 35830; i) C. G. Pappas, I. R. Sasselli, R. V. Ulijn, Angew. Chem. Int. Ed. 2015, 54, 8119; j) M. P. Friedmann, V. Torbeev, V. Zelenay, A. Sobol, J. Greenwald, R. Riek, PloS one 2015, 10, e0143948; k) A. J. Burton, A. R. Thomson, W. M. Dawson, R. L. Brady, D. N. Woolfson, Nat. Chem. 2016, 8, 837; I) G. Gulseren, M. A. Khalily, A. B. Tekinay, M. O. Guler, J. Mater. Chem. B 
2016, 4, 4605; m) Y. Maeda, J. Fang, Y. Ikezoe, D. H. Pike, V. Nanda, H. Matsui, PloS one 2016, 11, e0153700; n) M. Wang, Y. Lv, X. Liu, W Qi, R. Su, Z. He, ACS Appl. Mater. Interfaces 2016, 8, 14133; o) Y.-M. Wong, H. Masunaga, J.-A. Chuah, K. Sudesh, K. Numata, Biomacromolecules 2016, 17, 3375; p) A. M. Garcia, M. Kurbasic, S. Kralj, M. Melchionna, S. Marchesan, Chem. Commun. 2017, 53, 8110; q) R. Song, X. Wu, B. Xue, Y. Yang, W. Huang, G. Zeng, J. Wang, W. Li, Y. Cao, W. Wang et al., J. Am. Chem. Soc. 2018.

[12] D. Zaramella, P. Scrimin, L. J. Prins, J. Am. Chem. Soc. 2012, 134, 8396.

[13] T. Darbre, J.-L. Reymond, Acc. Chem. Res. 2006, 39, 925
[14] N. Singh, M. P. Conte, R. V. Ulijn, J. F. Miravet, B. Escuder, Chem. Commun. 2015, 51, 13213

[15] a) B. Escuder, F. Rodríguez-Llansola, J. F. Miravet, New J. Chem. 2010 34, 1044; b) X. Du, J. Zhou, J. Shi, B. Xu, Chem. Rev. 2015, 115, 13165

[16] a) R. Sure, S. Grimme, J. Comput. Chem. 2013, 34, 1672; b) J. G. Brandenburg, M. Hochheim, T. Bredow, S. Grimme, J. Phys. Chem. Lett. 2014, 5, 4275

[17] a) M. Brandl, M. S. Weiss, A. Jabs, J. Sühnel, R. Hilgenfeld, J. Mol. Biol. 2001, 307, 357; b) M. Nishio, J. Mol. Struct. 2012, 1018, 2. 